\title{
BUCKILING ASSESSMENT OF SHIP HULL CONSTRUCTION PLATE EMENETS UNDER THE SIMULTANEOUS ACTION OF BENDING AND SHEAR LOADINGS
}

\author{
ОЦНКА СТІЙКОСТІ ПЛАСТИНЧАТИХ ЕЛЕМЕНТІВ КОРПУСНИХ \\ КОНСТРУКЦЙ В УМОВАХ ОДНОЧАСНОЇ ДІї ЗГИНАЛЬНИХ \\ ТА ЗСУВНИХ НАВАНТАЖЕНЬ
}

\author{
Leontiy I. Korostlyov \\ leontyy.korostilyov@nuos.edu.ua \\ ORCID: 0000-0002-4370-3270 \\ Yaroslav O. Martychenko \\ Grapua@gmail.com \\ ORCID: 0000-0002-3027-5115
}

\author{
Л. І. Коростильов, \\ докт. техн. наук, професор
}

Я. О. Мартиченко,

аспірант

\author{
Admiral Makarov National University of Shipbuilding, Mykolaiv \\ Національний університет кораблебудування імені адмірала Макарова, м. Миколаїв
}

\begin{abstract}
Modern draft methods and documents of classification societies, for the most part, recommend assessing the stability of plate elements separately from each type of load, which can lead to loss of plate stability. With the help of theoretical calculations, the falsity of this approach was proved. In this work, the calculations of the stability of plate elements with cutouts at simultaneously acting on them bending and shear loads are performed. The influence of different aspect ratio, as well as the size of the centrally located round cut on the stability of the plates is analyzed. A series of boundary curves is constructed, which describe the characters of the influence of the simultaneous action of the above loads on the stability of rectangular plates. This scientific work is one of a series of studies of the stability of plate elements of hull structures, which are currently performed at the Department of Structural Mechanics and Hull Construction at the Admiral Makarov National University of Shipbuilding.

Purpose. The aim of the work is to perform the analysis of the stability of rectangular plates under conditions of simultaneous action of bending $\sigma 0$ and shear $\tau$ loads and to evaluate the influence of central round cutouts of different sizes on the stability of such plates.

Method. Using the finite element method, the stability of hinged rectangular plates with a centrally located round cutout of different diameters under the simultaneous action of bending $\sigma 0$ and shear $\tau$ loads was numerically investigated.

Results. A series of boundary curves is constructed, the shape of which is closest to the calculation results. The analysis of results is carried out and formulas for designing of plate elements at difficult loading are developed.

Scientific novelty. The obtained results allow a more accurate assessment of the stability of the plate elements under the action of a complex load.

Practical importance. The results of scientific research can be used to improve techniques for the design of hull structures.
\end{abstract}

Key words: plate; cutout; buckling; bending; shear; two-component loading; boundary curve.

Анотація. Сучасні проєктні методики та документи класифікаційних товариств здебільшого рекомендують виконувати оцінку стійкості пластинчатих елементів окремо від кожного типу навантаження, що здатне призвести до втрати пластиною стійкості. За допомогою теоретичних розрахунків була доведена хибність такого підходу. У цій роботі виконано розрахунки стійкості пластинчатих елементів із вирізами в разі згинальних і зсувних навантажень, що діють на них одночасно. Проаналізовано вплив різного співвідношення сторін, а також розміру розташованого в центрі круглого вирізу на стійкість пластин. Побудовано серію граничних кривих, які описують характер впливу одночасної дії зазначених вище навантажень на стійкість прямокутних пластин. Ця наукова робота є однією із серії досліджень стійкості пластинчатих елементів корпусних конструкцій, що нині виконуються на кафедрі будівельної механіки і конструкції корпусу корабля в Національному університеті кораблебудування імені адмірала Макарова.

Мета. Метою роботи є виконання аналізу стійкості прямокутних пластин в умовах одночасної дії згинального б0 і зсувного $\tau$ навантажень та оцінка впливу центральних круглих вирізів різних розмірів на стійкість таких пластин. 
Метод. За допомогою методу скінченних елементів чисельно досліджено стійкість шарнірно обпертих прямокутних пластин із центральним круглим вирізом різних діаметрів у разі одночасної дії згинального б0 і зсувного $\tau$ навантажень.

Результати. Побудовано серію граничних кривих, форма яких найбільш наближена до результатів розрахунку. Проведено аналіз результатів і розроблено формули для проєктування пластинчатих елементів у разі складного навантаження.

Наукова новизна. Отримані результати дають змогу точніше оцінити стійкість пластинчатих елементів у разі дії на них складного навантаження $\sigma 0$ i $\tau$.

Практична значимість. Результати наукових досліджень можуть бути використані в процесі вдосконалення практичних методик проєктування корпусних конструкцій суден.

Ключові слова: пластина; виріз; стійкість; згинання; зсув; двокомпонентне навантаження; гранична крива.

\section{ПОСТАНОВКА ПРОБЛЕМИ}

Під час проведення планових ремонтних робіт баржі проєкту «NBL-001» на суднобудівельному заводі Нібулон була поставлена задача виконати оцінку можливості підйому такої баржі на візках короткого сліпу підприємства [1]. Довжина підйомного пристрою була значно меншою за довжину баржі, тому такий підйом потрібно було здійснювати за наявності значних звисаючих частин. У цьому випадку навантаження від крайнього візка на стінку флора призводить до одночасної дії згинального та зсувного напружень. Від окремої дії кожного із зазначених напружень стійкість стінки флора забезпечувалась відповідно до чинних нормативних документів [2-3]. Врахування фактора одночасної дії цих напружень довело неможливість виконання підйому баржі саме через незадоволення умов стійкості при допустимому коефіцієнті запасу стійкості $[\eta]=1,5$.

Одночасна дія згинального та зсувного навантажень пластинчатих елементів характерна для більшості елементів поперечного набору корпусу судна, таких як стінки флора, бімса тощо. Саме тому коректне виконання аналізу стійкості таких елементів при цьому типі навантаження є актуальною задачею.

\section{АНАЛІЗ ОСТАННІХ ДОСЛІДЖЕНЬ І ПУБЛІКАЦІЙ}

Проблема оцінки стійкості конструктивних елементів в умовах складного навантаження була сформульована професором П. Ф. Папковичем у 30 -х роках минулого століття [4]. Ним були доведені теореми, що показують характер впливу одночасної дії кількох навантажень на пластинчатий елемент у вигляді граничних поверхонь, це дало поштовх для подальший досліджень у цьому напрямі.

У 60-х роках минулого століття значний внесок у вирішення цієї проблеми був зроблений професором А. С. Вольмиром. Він запропонував формули, які наближено описують граничні криві за умов різних типів складного навантаження [5].

Наприкінці 70-х років проблемою оцінки стійкості в разі складного навантаження почали займатись у Миколаївському інституті кораблебудування (нині Національний університет кораблебудування ім. адм. Макарова) [6]. Також стійкість при одночасній дії згинальних і зсувних напружень у площині пластини досліджували за кордоном [7].

Нині теоретичні і експериментальні дослідження стійкості пластинчатих елементів із вирізами в умовах складного навантаження продовжують виконуватись на кафедрі будівельної механіки та конструкції корпусу корабля Національного університету кораблебудування імені адмірала Макарова [1; 8].

МЕТОЮ РОБОТИ є виконання аналізу результатів розрахунків стійкості прямокутних пластин в умовах одночасної дії згинального $\sigma 0$ і зсувного $\tau$ напружень та оцінка впливу центрального круглого вирізу різних розмірів на стійкість таких пластин.

\section{ВИКЛАД ОСНОВНОГО МАТЕРІАЛУ}

Оцінку стійкості шарнірно обпертого пластинчатого елементу виконано за допомогою методу скінчених елементів. Товщина пластини $t=10 \mathrm{мм}$, модуль лінійної пружності $E=2,1 \times 10^{11}$ Па, коефіцієнт Пуассона $\mu=0,3$, співвідношення сторін $\gamma=a / b$, центральний круглий виріз із діаметром d. Розрахункова схема пластинчатого елемента при одночасній дії згинального $\sigma_{0}$ i зсувного $\tau$ навантажень наведена на рисунку 1.

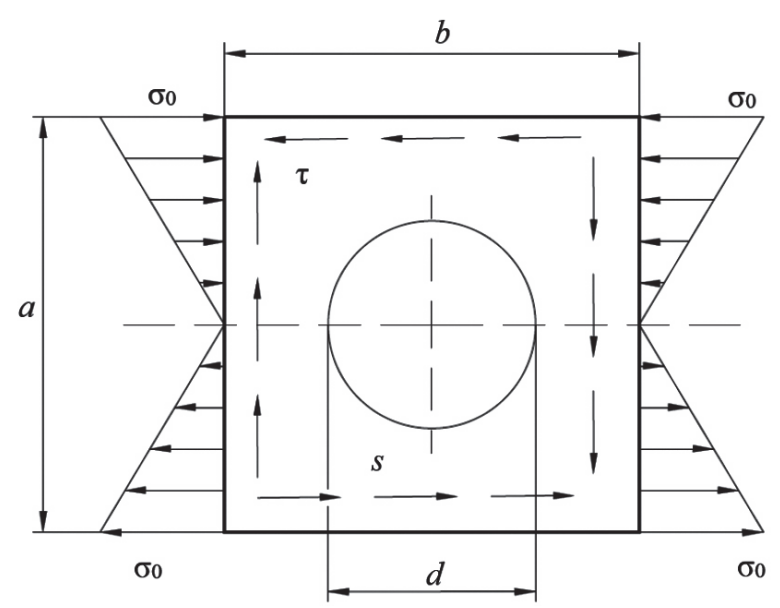

Рис. 1. Розрахункова схема пластинчатого елемента 


\section{СУДНОБУДУВАННЯ № 4 - 2021}

Характер впливу двокомпонентного навантаження на пластину описується граничною кривою. У галузевому стандарті [3] було запропоновано таку криву представляти у вигляді прямої

$$
\frac{\sigma_{0, c r}^{*}}{\sigma_{0, c r}}+\frac{\tau_{c r}^{*}}{\tau_{c r}}=1
$$

де $\sigma_{0, c r}^{*}, \tau_{c r}^{*}-$ ейлереві критичні напруження при одночасній дії $\sigma_{0}$ i $\tau$;

$\sigma_{0, c r}, \tau_{c r}-$ ейлереві критичні напруження при окремо діючих $\sigma_{0}$ i $\tau$.

Граничну криву для суцільних пластин в умовах аналогічних навантажень А. С. Вольмиром [4] запропоновано описати формулою

$$
\left(\frac{\sigma_{0, c r}^{*}}{\sigma_{0, c r}}\right)^{2}+\left(\frac{\tau_{c r}^{*}}{\tau_{c r}}\right)^{2}=1 .
$$

Розрахунок проводився при різних комбінаціях напружень $\sigma_{0}$ i $\tau$ для суцільних пластин із різними співвідношеннями сторін $\gamma$ і з центрально розташованими круглими вирізами з $\delta=a / d=0,1 \ldots 0,5$ (рис. 1 ). Отримані результати розрахунків представлені в графічному вигляді на рисунках 2-4.
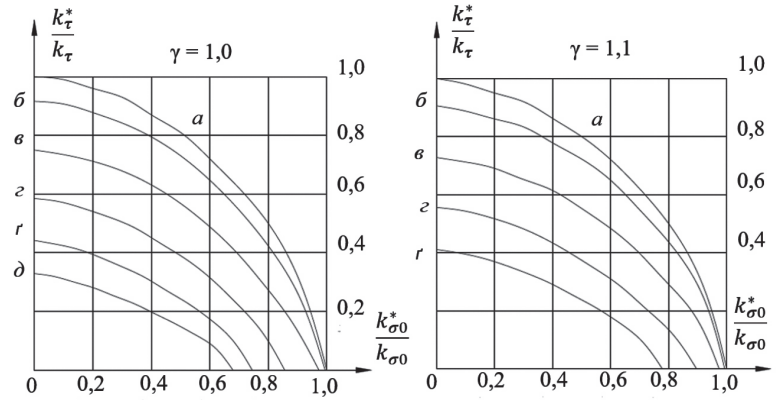

Рис. 2. Граничні криві для пластин зі співвідношенням сторін $\gamma=1,0$ та $\gamma=1,1$ вирізом із різними співвідношеннями $\delta=a / d: a-$ суцільна пластина; $\sigma-\delta=0,1 ; \beta-\delta=0,2 ; 2-\delta=0,3$
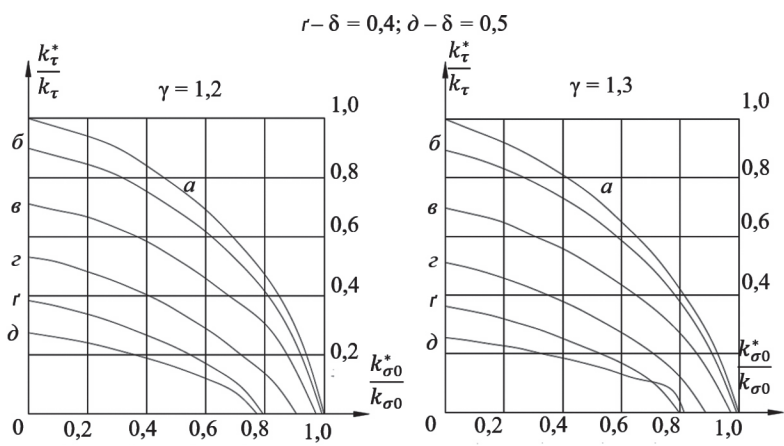

Рис. 3. Граничні криві прямокутних пластин 31 співвідношенням сторін $\gamma=1,2$ та $\gamma=1,3$ вирізом із різними співвідношеннями $\delta=a / d$ :
На основі аналізу отриманих результатів запропонована наближена формула для граничної поверхні пластинчатого елемента корпусних конструкцій із круглими вирізами

$$
\left(\sigma_{0, c r} \cdot \frac{\sigma_{0, c r}^{*}}{\sigma_{0, c r}^{o}}\right)^{1,5}+\left(\tau_{c r} \cdot \frac{\tau_{0, c r}^{*_{o}}}{\tau_{0, c r}^{o}}\right)^{1,5}=1,
$$

де $\sigma_{0, c r}^{* o}, \tau_{0, c r}^{* o}-$ критичні напруження пластини з вирізом при одночасній дії $\sigma_{0}$ i $\tau$;

$\sigma_{0, c r}^{o}, \tau_{0, c r}^{o}-$ критичні напруження пластини з вирізом при окремій дії $\sigma_{0}$ i $\tau$.

На рисунку 5 представлено порівняння результатів розрахунків за наближеною формулою (3) і отриманих методом скінченних елементів для часткового випадку при $\gamma=1,5$ при різних розмірах вирізу $\delta$

Отримані результати за допомогою формули (3) дають змогу наближено представляти граничні криві при зазначених вище навантаженнях із помилкою в небезпечну сторону, яка не перевищує $3 \%$ для пластин із вирізами. Для суцільних пластин більш точним буде зменшення показників ступеня з 1,5 до 1,3.

\section{ВИСНОВКИ}

Отримані результати і, відповідно, формула (3) дають змогу точніше виконувати оцінку стійкості пластинчатих елементів із центрально розташованим
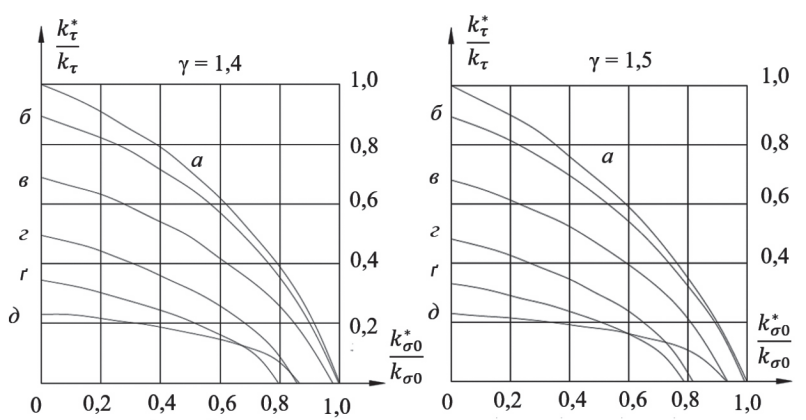

Рис. 4. Граничні криві прямокутних пластин зі співвідношенням сторін $\gamma=1,4$ та $\gamma=1,5$ вирізом із різними співвідношеннями $\delta=a / d$ :

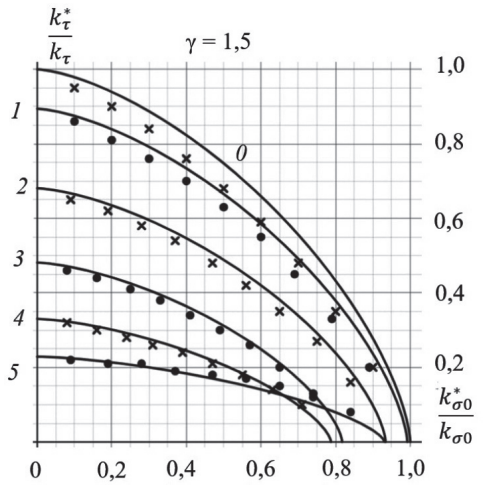

Рис. 5. Представлення формули (3) для пластини зі співвідношенням сторін $\gamma=1,53$ круглим вирізом різного діаметра: 0 - суцільна $(\delta=0) ; 1-\delta=0,1 ; 2-\delta=0,2 ; 3-$ $\delta=0,3 ; 4-\delta=0,4 ; 5-\delta=0,5$ 
круглим вирізом у разі одночасної дії на них згинального та зсувного навантажень.

Оцінка стійкості від дії окремого типу навантажень дає значну похибку в небезпечну сторону.

Наявність вирізу має значний вплив на зниження стійкості при дії зсувних і згинальних напружень, наявність вирізу зі співвідношенням $\delta=0,1$ знижує стійкість на $10 \%$, а при $\delta=0,5$ - більше ніж на $50 \%$.

Подальші дослідження будуть спрямовані на оцінку стійкості пластинчатих елементів у разі трикомпонентного навантаження.

\section{REFERENCES}

[1] Martychenko Ya. O., Korostyl'ov L. I. (2016). O prochnosty korpusa sudov pry pod"eme na korotkom slype [About ship hulls strength during the lifting on the short slip way]. Sbirnyk naukovykh prats' NUK, 24-28.

[2] Rehistr sudnoplavstva Ukrainy (2011). Pravyla klasyfikatsii ta pobudovy morskykh suden. Tom 2. Kyiv.

[3] RD 5.1037-80 (1980). Nabor sudovoy. Vyrezy v nabore. Normy i pravila proyektirovaniya [Ship's set. Cutouts in the set. Norms and rules of design].

[4] Papkovich, P. F. (1941). Stroitelnaya mekhanika korablya CH.2 [Structural mechanic of the ship. Part 2]. Leningrad: Gosudarstvennoye soyuznoye izdatel'stvo sudostroitel'noy promyshlennosti.

[5] Vol'mir, A. S. (1967). Ustoychivost deformiruyemykh sistem [Buckling of deforming systems]. Moskva: izdatel'stvo «Nauka».

[6] Korostylov, L. I. (1984). Eksperimentalnoye issledovaniye ustoychivosti plastin s vyrezami pri kombinirovannykh nagruzkakh [Experimental research of plates with cutouts buckling under complex loading]. Sbornik nauchnykh trudov NKI, 19-23.

[7] Brown, C. J., Yettram, A. L. (1986). The Elastic Stability of Square Perforated Plates Under Combinations of Bending, Shear and Direct Load. Thin-Walled Structures, 4, 239-246.

[8] Martychenko Ya. O., Korostyl'ov L. I. (2021). Otsinka stiykosti plastynchatykh elementiv korpusnykh konstruktsiy v umovakh odnochasnoyi diyi styskayuchykh ta zsuvnykh napruzhen' [Buckiling assessment of ship hull construction plate emenets under the simultaneous action of compressive and shear stresses]. Sbirnyk naukovykh prats' NUK. № 2, 8-1.

\section{СПИСОК ВИКОРИСТАНОЇ ЛІТЕРАТУРИ}

[1] Мартиченко Я. О., Коростильов Л. І. (2016). О прочности корпуса судов при подъеме на коротком слипе. Збірник наукових працьь НУК. С. 24-28.

[2] Регістр судноплавства України (2011). Правила класифікації та побудови морських суден. Том 2. Київ.

[3] РД 5.1037-80 (1980). Набор судовой. Вырезы в наборе. Нормы и правила проектирования.

[4] Папкович, П. Ф. (1941). Строительная механика корабля. Ч. 2. Ленинград : Государственное союзное издательство судостроительной промышленности.

[5] Вольмир, А. С. (1967). Устойчивость деформируемых систем. Москва : издательство «Наука».

[6] Коростылёв, Л. И. (1984). Экспериментальное исследование устойчивости пластин с вырезами при комбинированных нагрузках. Сборник научных трудов НКИ. С. 19-23.

[7] Brown, C. J., Yettram, A. L. (1986). The Elastic Stability of Square Perforated Plates Under Combinations of Bending, Shear and Direct Load. Thin-Walled Structures, 4, pp. 239-246.

[8] Мартиченко Я. О., Коростильов Л. І. (2021). Оцінка стійкості пластинчатих елементів корпусних конструкцій в умовах одночасної дії стискаючих та зсувних напружень. Збірник наукових праць НУК. № 2. С. 8-1. 